\title{
Relational Ontologies and the Ground of Life
}

Dialogues in Human Geography 2016, Vol. 6(1) 103-105

Nigel Clark

\section{Book Review Forum}

Irus Braverman, Wild Life: The Institution of Nature. Stanford University Press, 2015

Jamie Lorimer, Wildlife in the Anthropocene: Conservation after Nature. University of Minnesota Press, 2015;

\footnotetext{
Abstract

This commentary on Irus Braverman's Wild Life (2015) and Jamie Lorimer's Wildlife in the Anthropocene (2015), raises some questions about the movement between the authors' own relational ontologies and the pragmatic or improvised ontologies that surface in their respective ethnographic accounts. It also asks whether an apparent allegiance to an undefiled 'Nature' on the part of some conservationists might be viewed not only in terms of relational networks but also as kind of ontological commitment to the 'ground' of life.
}

\section{Keywords}

Wild life, conservation, ontology, relational materialism, Anthropocene 
Seeking to quantify the global impact of intensifying human land-use, environmental scientist Earle Ellis and his colleagues have charted the conversion of natural 'biomes' into human-dominated 'anthromes' between the years 1700 and 2000. As their data indicates: ‘Most of Earth's unused lands are now embedded within the agricultural and settled landscapes of seminatural, rangeland, cropland and village anthromes' (Ellis et al, 2010: 599). While such broad brushstrokes may convey the magnitude of threats to wild lives, they reveal little about what it is like to dwell in this compromised landscape. Or what it might mean to try and live well with nonhuman others under such conditions.

This is where these two poignant and provocative books offer more intimate perspectives, inviting us into the world of snub-nosed amphibians, corncrakes, snot otters and a no-less lively cast of conservation biologists, park managers, activists and volunteers. Distinct in other regards, Irus Braverman's Wild Life (2015) and Jamie Lorimer's Wildlife (2015) both lead us from the planet-spanning scale of Anthropocene diagnostics to the day to day experience of managing 'the wild'; guiding us through situations where experts and ordinary people struggle to save individual organismic lives and to hold open evolutionary pathways. But both authors also move out again, and ask what these paradoxical practices of protecting wild lives in un-wild spaces tell us more generally about how nature and culture are being reconceptualised at the current earth-historical juncture.

More of an armchair observer of wild things myself, I'm interested in how the rich ethnographic accounts offered by Lorimer and Braverman articulate with their own thoughts on the contemporary spatio-temporal relationship between nature and society. Both books advance versions of what fellow-travelling critical geographers would recognise as relational ontologies. 'Connectivity' observes Lorimer, 'is a new watchword for conservation' .... the principle metaphor used to describe these emerging topologies is the network' (2015: 170). The alternative to the 'rigid bifurcations of "in" and "out" of nature', as Braverman would have it, is an affirmation of 'the messy and productive entanglements of wild life' (2015: 232).

At the same time, each author goes to some lengths to locate much of the real work of renegotiating culture-nature relations in the mud-spattered particularity of practice. This prompts some questions about what it means, as a researcher, to have an ontology 
of one's own - any sort of ontology - and how this relates to the more specific and situated constructions that often turn up in the course of our research. But I'm also interested in the ontologies themselves. Is a relational ontology that mutually implicates the natural and the cultural the only way out of recourse to the grand referent of Nature? Or might there be something else going on in these fraught and fertile stories from the frontline of the wild life management?

In Wildlife, Lorimer distinguishes conservation practitioners with a preference for the supposed 'equilibria' characteristic of premodern (or even prehuman) ecologies from those who have come round to a more nonlinear understanding of human-nonhuman relations - a relational perspective in which novelty, surprise and resilience are seen to be emergent properties of messy entanglements. But the book also conveys a sense that, in practice - whatever their onto-political commitments or institutional directives most field-working conservationists seem to deploy 'a practical "intuitive ontology" that blurs hard ontological divides (Lorimer, 2015: 69). In the rough, they modify scripts, compromise, improvise. In Braverman's narrative, respective allegiances to in situ or ex situ conservation at first seem to imply sharply conflicting conceptions of the nature-culture interface. But as she recounts:

In the process of researching and writing Wild Life, I observed a curious discrepancy between the fidelity of many of my interviewees toward the ideals of nature and wilderness, and the ways in which their actual management practices reflect the messiness and pluralities of these constructs (2015: 11).

Interesting. And understandable. But if in the 'real world', ontology is there to be bypassed, reconstructed, retrofitted, what does that mean for those of us of a more theoretical bent? Where does it leave specialists in critical and speculative thought whose own worldly practices are indeed invested in the composing and embroidering of onto-stories? Should we human geographers, for example, be weighing in with the full heft of the relational materialist turn behind us, or should we be easing off and waiting to see what whiffs of ontology or metaphysics rise from the miasma of the everyday? As Clive Barnett (2008) has noted, there has been a strong `ontological drift' in recent critical thought, such that is often assumed that it is vital to get our own onto-stories sorted out in advance of knowledge-gathering or political ventures. 'It is supposed,' he skeptically observes, 'that inquiry can and must be preceded by clearly 
delimiting the general metaphysical properties possessed by objects of analysis' (2008: 187).

But the beauty of the ethnographic accounts at the core of Braverman and Lorimer's respective outings is that they provide opportunities for the authors' own ontological inclinations to rub against a raft of ingrained, emergent or cobbled-together ontostories and normative orientations. Understandably, when they've cleaned the mud off their boots, both authors tend to come back to preferences for impure, improvised and experimental worldviews that they probably held at the outset. As you do. But the journeys are interesting ones, circuitous and tangled enough to offer a range of possible readings, engagements, speculations.

It is here that I want to indulge one of my own ontological presuppositions and ask whether there might be possibilities fermenting in the ethnographic richness of both texts that exceed 'relational' interpretations. Is an ontology and praxis centred on connectivity, networking, entanglement the only alternative to what are now deeply, discredited notions of originary plenitude? The advantage of relational ontologies, as critical geographers well know, is that they hold open the potential for recomposing reality, for putting things together in new and exciting ways. The assumption being that relational networks are the preeminent sites at which surprise and novelty emerge. There are many theorists, however, who are profoundly dismissive of bicameral nature-culture constructions but who nonetheless look beyond or beneath networked relations in their quest for the wellspring of the new.

As geographer Kai Bosworth would have it, novelty comes not just out of shifting relations and connections, but from `a surplus of potentiality exhibited by the Earth.' 'In order for this surplus to exist,' he insists, 'it must not be essentially connected to every other part of the earth system' (2013: fn 4). What Bosworth is getting at here is the idea of the Earth and its processes as a 'ground'. A ground, that is, not in the old deterministic sense, but as a field or domain of possibility that is always in excess of the actual things to which it gives rise - whether these are relations, networks or objects.

Whereas it tends to be assumed that networked relations are at least partially within reach of the entities that compose them, grounding conditions are usually taken to be antecedent to their productions - such that no being can re-enact, recover or even fully 
access the preconditions of its own emergence. While Deleuzean notions of virtuality and Derridean ideas of indefinitely receding 'originary complications' might be taken as versions of a kind of ungrounding ground, Bruno Latour offers a more recent consideration of grounding conditions. Distancing himself from his own previous prioritization of network relations, Latour has lately been exploring modes of existence that explicitly 'precede the human, infinitely' (2013: 15; see Conway, 2015). He now writes of 'the return of object and subject back to the ground ' (2014: 16, my italics), proposing a "metamorphic zone" where we are able to detect actants before they become actors ... where "metamorphosis" is taken as a phenomenon that is antecedent to all the shapes that will be given to agents' (2014:13).

None of this is to deny the importance of networks, relations, assemblages and some possibility of enacting them otherwise - in conservation or any other practice. But I am wondering if some of those conservationists Braverman or Lorimer speak of may not simply be dreaming of originary purity so much as trying to articulate - in the terminology they have at hand - some kind of fidelity to the profound, unfathomable and excessive earthly conditions out of which currently existing biological life has emerged. In other words, when they speak of wildlife in situ, of wild-lands or premodern ecologies, what they may be gesturing towards is not so much 'Nature’ separate, pure and intact, but something more like potentiality itself, the ungraspable conditions of grounding, those modes of existence that 'precede the human, infinitely'.

Is this a world away from Lorimer's admission that 'the generative potential of nonhuman difference is a vital source of value' (2015: 181), or from Braverman's unwillingness to countenance ‘abandoning nature altogether' (2015: 11). Probably not. But it may be helpful - if perturbing - to think of the predicament of life in the Anthropocene not only in terms of spatial relations of interconnectivity and mutual enfoldings, but also as the partial undoing of an earthly ground, as the erosion of conditions that by virtue of their radical anteriority defy full recuperation. Whether the bold experiments of the new generation of ecologists are last ditch attempts to wring some novelty out of a disappearing substratum or whether they are part of the accretion of some kind of new ground is open to question. Either way, a degree of mournfulness and nostalgia on the part of wildlife managers might well be excusable.

\section{References}


Barnett C (2008) Political affects in public space: Normative blind-spots in nonrepresentational ontologies. Transactions of the Institute of British Geographers 33: 186-200.

Bosworth K (2013) Notes towards a geological uprising by way of a dark feminism. Society and Space http://societyandspace.com/reviews/reviews-archive/woodard-2013kai-bosworth/ (accessed 27 January 2015).

Braverman, I (2015) Wild Life: The Institution of Nature. Stanford, CA.: Standford University Press.

Conway P (2015 forthcoming) Back down to Earth: Reassembling Latour's Anthropocenic geopolitics, Global Discourse.

Ellis E, Goldewijk K, Sieber S, Lightman D and Ramankutty N (2010) Anthropogenic transformation of the biomes, 1700 to 2000. Global Ecology and Biogeography, 19: 589-606.

Latour B (2013) An Inquiry into Modes of Existence: An Anthropology of the Moderns. Cambridge, Mass.: Harvard University Press.

Latour B (2014) Agency at the Time of the Anthropocene. New Literary History 45 (1): $1-18$.

Lorimer, J (2015) Wildlife in the Anthropocene: Conservation after Nature. Minneapolis: University of Minnesota Press. 